\title{
RESOURCE UTILITY FOR EFFECTIVE SCIENCE EDUCATION IN NIGERIA:THE CASE OF BIOLOGY
}

\author{
Jacinta A. Opara \\ Center for Environmental Education, Universidad Azteca Chalco-Mexico \\ E-mail address: nkasiobisilasoguzor@yahoo.com
}

Keywords: Resources; Utilization; Teaching; Learner

\begin{abstract}
Resource utilization, curriculum innovation and professional development courses are integral to improve educational practices as they empower teachers with knowledge and skills required for integrating education and society. Such moves and actions need to be guided with research. The education practices in Nigeria need to be sound and grounded. This paper is concerned with the importance of the use of resources for effective understanding of school science with special reference to biology. It identified necessary resources, constraints and how to select and use resources for effective teaching and learning of biology. The selection and utilization of any resources depends on the specific features of a particular topic. Therefore, different sets of resources and strategies are needed to teach different topics.
\end{abstract}

\section{INTRODUCTION}

West African Examination Council (WAEC,2010) revealed that achievement of students in biology, chemistry and physics in May/ June examinations has been on the decline. Of the total number of students who sat for the examination in the year under review, the total percentage of candidates who attained credit level (grade 1-6) and above in Biology, Chemistry, and Physics averaged $26 \%, 34.92 \%$ and $22.61 \%$ while $53.13 \%, 43.79 \%$ and $45.49 \%$ respectively failed.

Biology as a curriculum subject, had witnessed a high level enrolment than any other science subjects in the final year external examinations (James and Awodi, 1997).Conversely, there has not been a corresponding increase in students' performance in the examinations. The poor performance of students in biology has been attributed to poor teaching methods in the form of excessive talking, coping of notes and rote learning of text book materials adopted by science teachers (Opara,2014A)..

These students are exposed to expository than inquiry methods of biology which does not predispose students to experimentation (Anulobi, 2009, Opara and Ejifugha,2014). The National Policy on Education (NPE, 2004), Stated that the aim of education is to inculcate in the child, the spirit of inquiry and creativity through the exploration of nature. That education should equip students with skills with which to live effectively in our modern age of science and technology. In line with the above objective, one of the aims of biology is to develop in students the ability to think critically in order to make reasonable decisions in issues that concern them, and the society at large. Research findings in biology tend to indicate that the instructional materials adopted by teachers do influence the cognitive, psychomotor and affective outcomes of the students. Instructional materials perform specific functions in learning such functions ranges from simplifying teaching to making teaching effective (Ejifugha and Opara, 2015).

However, the teaching and learning of biology is an activity whose success is determined by host of factor among them are the nature and availability of necessary resources and also the teacher factor which is probably the most critical. The biology teacher should be able to select and use these resources depending on the specific features of that particular topic 


\section{RESOURCES FOR TEACHING AND LEARNING}

Resources as regards to teaching and learning according to Awolola (2000) are those human and materials inputs necessary for achieving the objectives of concepts to be taught. It is the sum total of everything used directly or indirectly for the purpose of educational training to facilitate or encourage the acquisition of knowledge competence, skill and know - how (Akinsola, 2000,Opara,2014B and Opara,2014C ).

It is important to select and make effective use of learning and teaching resources. Biology teachers in schools need to select, adapt and develop resources to support students' learning. Effective selection and utilization of resources will help students to consolidate what they have learned, extend and construct knowledge for themselves and develop strategies and skill for learning. There are many learning and teaching resources for biology. Resources or teaching materials as they may be called are classified into five categories (Adobel, 2000).

They are as follows:-

1. People: teachers and students

2. Materials: textbook, models etc

3. Tools and equipment: chalkboard, slide projectors computer based instruction etc

4. Settings: school building, garden, space, library

5. Activities: games, field trips, excursions etc

Teachers in different schools especially in developed countries of the world are trying out new concepts such as team teaching, automated learning and computer - assisted instruction. New building spaces and building facilities that group students and provide them with alternative units of instruction to achieve learning objectives are now available

The role of resources in teaching and learning process in schools cannot be emphasized. It facilitates learning and ensures active involvement of the students in the learning process. It becomes imperative that in designing instructional materials, efforts have to be made to include the criteria for the three domains of educational objectives, so as to integrate the overall achievement of learning. This implies considering the age, ability, interest as well as its production cost and availability in the teaching environment. Babalola(2004) explained that these resources are designed to promote and encourage effective teaching and learning experiences.

Designing biology teaching and learning are aimed to use the "mixture" of learning "ingredient" that guarantees high quality knowledge for the learner by selecting and utilizing appropriate resources. This requires adhering to the designing principles which includes - selecting objectives; selecting materials; analyzing students; utilizing materials; student's participation and evaluating students(Opara,2014D). All in all, different sets of resources and strategies are needed to develop instruction for different topics for effective teaching and learning

\section{RESOURCES UTILIZATION IN SCIENCE TEACHING AND LEARNING}

1. The Use of Instructional Materials. The biology teachers can provide the students with three dimension models related to the current area of study in biology for instance, the scale model of human anatomy, such as the human skeleton, muscular system and nervous system to show students the parts of human body. He can also use the scale models of animals and insects to provide student with a deeper understanding in the branches of biology like entomology, zoology etc. This three dimensional materials also called realistic models, which could also be used for plants which provides students with good instructional materials for the study of botany. To use three dimensional materials, it is essential to ensure that the material is large enough for general observation. Where it is practicable, models should not be used alone but in combination with other visual materials. For example, the use of model of a human heart can be augmented with the drawing of the same

2. Motion Pictures. A motion picture can be used to show the effect of the heartbeat on the flow of blood through the heart chambers. Such multi use of media needs proper planning and coordination for their effectiveness to be realized. 
3. Life Activities. The teachers expose students to experience biology as a science instead of just reading or listening about the subject. Develop a better and deeper connection with fields of biology, For instance, having a lizard or toad for an amphibian, presentation for distinguishing of dicotyledonous and monocotyledonous plants. Visualize the texture and weight of an object. The provision of various tools used in the study of biology employing life activities as;

a. The Instructor's Activities. The teacher should aim at making a learning course attractive, motivational and encourage the learners to earn as much knowledge as possible. For instance, to teach "pollination" the teacher can go with the students to the garden.

a) Look at the flowers;

b) Describe the flowers

c) What difference do you notice

d) what do you see on the flowers

- name the various visitors

- what do you think they are doing

- Touch the part of the flower they settle with your finger. Examine your finger. What do you see?

- Take the flower. Place your palm in front of your face. Place the flower between your face and the palm. Blow air on the flower. Blow it hard. What do you notice?

These activities illustrate the part the teacher plays in guiding the learner to achieve the objective. The learner is guided to recognize bright colors and to differentiate them from dull colours. He recognizes the different shapes of the flowers and also the insects that visit them. There is no guarantee that the students will give the right answer or any at all. The teacher modifies the questions, methods and also gives the right answers. However, this lesson is possible this way considering the appropriate season

\section{b.Students Activities.}

1) Walking to the school garden

2) Looking at the flowers

3) Describing the colours and shapes of the flowers

4) Comprising and contrasting both the shapes and colours of the flower

5) Naming the insects and birds that visit the flowers

6) Pointing out other flowers that have no visitors

7) Discussing the characteristics of the visitors e.g. long beaks

8) Touching the pollen dusts and describing how they stick to the fingers

9) Acting as an agent of pollination by blowing the wind or air. All these activities are observable and can be evaluated

4. Hands on Activities. The teachers provide students outlets for hands on activities and learning through special investigations in the current field of study of biology or branches of biology. Such as in microbiology, the provision of microscopes for microorganisms lessons. Engage students on field trips centered on a specific branch of study. For example, visit zoos, for zoology and aquariums for marine biology. The teacher can as well organize trips to visit inland waters for the study of limnology and recreational parks for studying environmental biology.

5. Matching and Observation. Observation occurs when students presented with a piece of materials they can touch, feel, and smell and possibly taste. This secondary school students can observe living organisms in their natural environment. This helps the students for better understanding of the living conditions some organisms thrive in. It encourages students to match it with other living condition of some other organisms. This is to enable them to compare and contrast these organisms. 
6. Computer Assisted Instruction and Computer Assisted Learning. These are good instructional resources which possess seeing and learning qualities that makes more effective teaching and learning. According to Alaku (1998) video play vital role in teaching and learning, when used effectively, it stimulates interest among the students and induces longer retention of factual ideas as they come into contact with what is being taught. The ease of electronic communication between teacher and students provide opportunity for sharing questions, answer and discussions during a course. The tremendous increases in rates of information transfer, access to the internet and posting of materials on the World Wide Web give teachers and students are almost limitless supply of resources material that could be used for all topics in biology. The CAL and CAI are of different types and covers different topics. There are commercial available package produced by experts in computer programming and the teacher -made packages or improvised instructional packages which are good and useful in teaching and learning of biology. The effectiveness, adaptability, malleability and versatility depend on how well the teacher has been prepared to handle it.

\section{CONSIDERATIONS IN SELECTING RESOURCES}

1) How the instructional resources fit in achieving the instructional objective of the lesson.

2) How the instructional resources present information for easy comprehension and clarity.

3) How the instructional resources are accessible within the locality for both the teacher and students.

4) How clear it will be based on the students' level of understanding?

5) How the students will use the resources to reach the instructional objective.

6) How the resource can be manipulated to present information in a variety of ways.

7) How the students feel about the resources.

8) How the resources could be used for effective and efficient evaluation at the end of the lesson.

9) Select resources with an accompanying study guide or interactive measures for additional learning opportunities

10) Select resources that are gender-neutral language and no stereotypes. Except otherwise, you point out the problems in the class and give the students an opportunity to discuss them

\section{CONDITIONS FOR RESOURCES SELECTION}

1) Objectives stated. Directed towards helping students achieve specific instructional objectives with a specific target population. It has to influence the cognitive, psychomotor and affective outcomes of the topic to the students. To make this skills more permanent and offer experiences, which promote self-activity on the part of the student. The proposed behavior the learner will pursue and acquire during the course of lesson, and manifest in observable manner when he completes the lesson.

2) Content. Alignment with the school curriculum, level of treatment, expertise for content development, accuracy of content, currency of content, authenticity of content, multicultural representation, humanity and compassion.

3) Appropriateness. It must meet the personal needs and interests of the students. It has to attract students' attention and sustain their interest thereby acquiring the necessary, recording, inquiring, controlling, inferencing, organization and generalization. It should have clarity in language and contextual visibility.

4) Presentation Proper organization of instructional resources. It is essential to ensure that the material is large enough for general observation. Comprehensiveness of student and teacher resources, readability of instructional materials, good pacing and valid content. 
5) Educative: instructional resources must be able drive the necessary information requires to the students. Teaching for effective understanding using motivational strategies. Making instruction explicit with targeted instructional and assessment strategies.

6) Durability - Ease to use and durable materials, the characteristics such that it can be portable, flexible, easy to manipulate, maintain and repair at ease.

7) Students - How many students are there, what are their general characteristics? The teacher should know his students in terms of their age, level, background, interest, and then individual differences. The teacher should make sure that the resources selected are fit or the student. This is because instructional resource appeals to the students based on these variables consideration.

8) Cost - Resources cost are often described based on their timing or their applicability. The teacher was to consider this while trying to compare the cost of instructional resources. It has to be less expensive and affordable but beneficial. A good creative and productive teacher should be able to make some instructional material through improvisation.

9) Learning Environment - Is the spaces large enough to allow for conveniently divide the students into small groups. Will it allow the students to work individually without distraction

10) Evaluative - These resources should be free of bias, stereotypes, distortions and prejudices for effective and efficient assessment. These resources could be used to determine the success or failure of a lesson based on the instructional objective. This will decide whether the teacher should continue with the same method or make changes where necessary.

\section{HINDRANCE TO EFFECTIVE RESOURCES UTILIZATION}

1) Lack of Instructional Resources: The teacher and the students will lack the opportunity to use them. If biology is properly taught with instructional resources, the students especially the less able ones will develop more positive attitudes to it. It will help the students see the relationship between biology and everyday activities of life, thus biology becomes more relevant and meaningful to student.

2) Time: The time that is allocated for a subject on the timetable might not be enough for the teacher to present the content alongside with effective use of the materials which will affect the wholesome delivery of the content.

3) Teachers Knowledge: Some teachers are not competent enough to use these resources for instructional purposes. The teacher should know the content of the lesson and its sequential presentation with the gadgets to suit the learners and its appropriateness with the instructional task. Stahl (2009) and Anyachebelu (2005) observed that majority of teachers are not well groomed and equipped for the task of teaching even at this age of information technology. Some teachers do not have the knowledge of the operational functionalities of some of these resources.

4) Lack of Fund: Some instructional resources require money to buy them. If there is no money the schools cannot afford them. This has also affected the production of some of these resources in which they are produced in an insufficient quality or quantity which makes them not readily available in the market.

5) Poor Power Supply: Most schools especially in the rural areas do not have access to electricity. The ones probably in urban areas with electricity have an incessant supply. The resources that require electricity to function are redundantly left to destroy. There is poor storage room and as a result these resources are improperly kept which cause their damages. 


\section{CONCLUSION}

Quality in education is synonymous with efficiency and effectiveness. It is only when the quality of input is ensured that the quality output can be dreamt of. The poor performance of students in biology has been attributed to poor teaching methods/strategies. In essence, effective resources selection and utilization in teaching and learning biology was seen as necessary for students in the acquisition of relevant cognitive, psychomotor, and affective skills, for greater achievement. This requires biology teacher exhibit teaching skill for the effective use of the teaching methods/resources for a worthwhile learning out come to be achieved. Sequel to the exposition made in this study, it is crucial that the selection and utilization of any resources depends on the specific features of the particular topic.

\section{References}

[1] Adobel .A. (200) Basic instructional Technology unpublished Hand book, Teacher Education series. Pp 6-7.

[2] Akisola, M.K on student' achievement in Geometry. Proceeding of $41^{\text {st }}$ Annual conference of STAN.

[3] Alaku, P.O. (1998) instructional strategies and is usual aids for teachers effectiveness, Bichi journal of Education 2 (1), 114-117.

[4] Anulobi, J.J.C (2009) Effective use of video compact disc parks age (VCDIP)on the academic performance of Junior Secondary school Fine Arts in Owerri. Journal Educational Technology and instruction (JETI) 1 (1) 31-36.

[5] Anyachebelu, E (2005) Educational psychology for effective strategies for improving learning in Schools. Lagos: Papyrus publishers

[6] Awolola J.B (2000) community Resources utilization in the teaching of integrated science. A paper presented at the National Work shop on integrated science, May 15-20.

[7] Babalola V.O (2004), Resource materials in the implementation of curriculum in $21^{\text {st }}$ century in Noah A.O.K (ed) curriculum implementation and professional teaching in Nigeria. Lagos: Central Educations services.

[8] Ejifugha,A.U and Opara, J.A (2015). "Adolescent Science Students' Perception of Acquisition of Environmental Health Skills Through School Health Programme in Nigeria". Journal of Educational and Social Research,Vol.5, no.1, January

[9] Federal Republic of Nigeria (2004). National Policy on Education. Abuja: NERDC press.

[10] James $\mathrm{T}$ and Awodi (1997) the relative affects of inquiring and lecture methods on the performance of high and low achievers in senior secondary school Biology. Journal of Science Teachers Association of Nigeria Vol. 32 No 1\&2, pp 59-64.

[11] Opara, J.A(2014A). "Socio-Psychological Assessment of Evaluation in Nigerian School System: The Question of Science Teachers' Leadership and Participation" Learning Community, Vol.5, No.2, August

[12] Opara, J.A(2014B). "Understanding the Motivation of the Nigerian Science Teacher for Sustainable Development". Mediterranean Journal of Social Sciences, Vol.5, No.26, pp.101106

[13] Opara,J.A(2014C). "Revisiting of Integrated Science Education in Rural Southern Nigeria: Perspectives on Job Status and Satisfaction" Techno Learn, Vol.4, No.2, December 
[14] Opara,J.A(2014D). "Bajah's Interdisciplinary Model and the Conceptualization of Integrated Science in Nigerian School Curriculum". Academic Journal of Interdisciplinary Studies, Vol.3, No.7, pp.96-101

[15] Opara, J.A and Ejifugha,A.U(2014). "Emerging Approach of Teaching School Science Through Inquiry Method". Journal of Educational and Social Research, Vol.4, No.7, pp.121137

[16] Stahl, S (2009). substance over learning styles. Journal of Review of educational research, $4(2), 228-232$

[17] www.ehow.effective.erc

[18] www.ehow.erc 